\title{
Presence of a biomaterial implant facilitates induction of experimental infective endocarditis due to streptococci and staphylococci
}

\author{
S. A. J. ZAAT*, J. DANKERT \\ Department of Medical Microbiology, Academic Medical Centre, 1105 AZ Amsterdam \\ J. VAN'DER WERFF, P. BROKKE \\ Department of Hospital Epidemiology, University Hospital Groningen, 9700 RB Groningen \\ J. FEIJEN \\ Department of Chemical Technology, University of Twente, 7500 AE Enschede, The \\ Netherlands
}

\begin{abstract}
Infective endocarditis (IE) usually is studied using animals with catheters inserted into the heart, which causes formation of platelet-fibrin thrombi (vegetations, VGs). We used two rabbit models to study the respective roles of the catheter and the VGs in the development of IE. The influence of the catheter was studied by either removing the catheter before bacterial challenge, or leaving the catheter in place. In all cases, removal of the catheter caused a strong decrease in the frequency of IE. The presence of the catheter stimulated population increase of streptococci within $4 \mathrm{~h}$ after challenge. As most catheters were sterile $4 \mathrm{~h}$ after challenge, they did not serve as a reservoir of bacteria. To study the requirement of a preformed VG catheters were inserted either $24 \mathrm{~h}$ or $30 \mathrm{~min}$ before bacterial challenge. In the former model VGs were present, in the latter VGs were not yet formed when bacteria were injected. The frequencies of IE due to $2 \mathrm{~S}$. sanguis and 2 S.epidermidis strains in the $24 \mathrm{~h}$ model or $30 \mathrm{~min}$ model were similar, indicating that a preformed VG is not necessary for development of IE. Five coagulase-negative stains were shown to vary in their capacity to cause IE in the 30 min model. Variation was not caused by differences in early adhesion or colonization of the aortic valve, but reflects differences in persistence after initial colonization. Like in the $24 \mathrm{~h}$ model, persistence of the bacteria was greatly enhanced by the continuous presence of the catheter. Possible mechanisms of the infection-potentiating effect of the catheters are discussed.
\end{abstract}

\begin{abstract}
1. Introduction
Infective endocarditis (IE) is an infection of the damaged endothelium of the heart. Cases of endocarditis can be divided into two categories, native and prosthetic valve endocarditis. In native valve endocarditis (NVE) the valve has been damaged by congenital defects or rheumatic fever. Bacteria, in most cases viridans streptococci which enter the circulation from the oral cavity, can adhere to VGs, platelet-fibrin depositions on the damaged heart valves or endothelium. The second category, prosthetic valve endocarditis (PVE), is associated with implantation of a prosthetic valve. PVE infections are further divided into early and late PVE, early PVE being defined as infections arising in the first year after surgery [1]. Staphylococcus epidermidis and other coagulase-negative (CN) staphylococci, and Staphylococcus aureus are the major causes of early PVE $[2,3]$.
\end{abstract}

In cxperimental animal models endocarditis can be induced by inserting a catheter into the heart [4]. The damage caused gives rise to formation of VGs. $\Lambda$ fter VGs are formed bacteria are injected, which colonize the VGs. In order to cause an infection, bacteria will have to persist and multiply at or in the VGs $[4,5]$, where they are protected from phagocytic cells. In addition to the $\mathrm{VG}$, the presence of a biomaterial like the catheter may potentiate infection. To study the respective roles of the VGs and the catheter, two models of endocarditis were used, in which catheters were implanted $24 \mathrm{~h}$ or only $30 \mathrm{~min}$ before injection of bacteria. In the $30 \mathrm{~min}$ model no VG was yet formed at the time of bacterial challenge.

\section{Materials and methods}

2.1. Bacterial strains and growth conditions Streptococcus sanguis type II strains 1 and 2 [5], as well as Staphylococcus epidermidis strains NCTC100835

* To whom correspondence should be addressed. 
(strain 1), NCTC100894 (strain 2), NCTC100892 (strain 3) and SL58 (strain 4), and Staphylococcus saprophyticus SAP1 have been used in previous experimental IE studies $[5,6]$. Inocula of streptococci and staphylococci grown overnight in Mueller Hinton $(\mathrm{MH})$ or tryptic soy broth (TSB), respectively, were prepared as described [5]. When grown in $\mathrm{MH}, S$. sanguis strains 1 and 2 are devoid of dextran [5]. Only $S$. epidermidis strain 4 produced slime, as judged by alcian blue staining of emptied overnight TSB culture tubes [7].

\subsection{Two different rabbit models of infective endocarditis}

(i) Viridans streptococcal endocarditis model: A polyethylene catheter (Portex, Hythc, Kcnt, UK) with external and internal diameters of $0.96 \mathrm{~mm}$ and $0.58 \mathrm{~mm}$ respectively was inserted via the lcft carotid artery into the left ventricle of New Zealand White rabbits weighing $2.1-3.1 \mathrm{~kg}$, as previously described [6]. To study the influence of the continuing presence of the catheter after bacterial challengc cathcters were lcft in place for $48 \mathrm{~h}$, or catheters were removed $24 \mathrm{~h}$ after placement. At $48 \mathrm{~h}$ after initial placement of catheters $10^{5} \mathrm{~S}$. sanguis strain 1 or 2 bacteria in $1 \mathrm{ml}$ PBS were injected into a marginal ear vein. This inoculum corresponded to the $90 \%$ infective dose (ID90) for $S$. sanguis strain $1[5]$.

(ii) Experimental model for early PVE due to $\mathrm{CN}$ staphylococci: Rabbits were catheterized either $24 \mathrm{~h}$ ("24 h PVE model") or 30 min ("30 min PVE model") prior to bacterial challengc. This way two markedly different models of early PVE were created. In the $24 \mathrm{~h}$ PVE model a VG had alrcady developed at the time of bacterial challenge. In the $30 \mathrm{~min}$ PVE model the endocardium and aortic valve (AV) were damaged, but no VG had yet formed. To study the influence of the continuing presence of the catheter after bacterial challenge, in both models the catheter was either left in placc or removed just before injection of bacteria. Bacterial inocula consisted of $10^{7} \mathrm{CN}$ staphylococci in $1 \mathrm{ml} \mathrm{PBS}$, being the ID90 of S. epidermidis strain 2 [7]; and were injected into a marginal ear vein.
2.3. Evaluation of bacterial colonization of VGs/AVs and catheters, and of infection At 5 or 30 min, or 2,4 , or $48 \mathrm{~h}$ after bacterial challenge rabbits were sacrificed and bacteria present in homogenized VGs or AVs. were quantitatively cultured as described [5]. IE was defined by culture-positivity of VGs at $48 \mathrm{~h}$. Catheter colonization was quantificd by culturing segments of catheters in pour plates, as described in [8].

Blood cultures: Blood $(5 \mathrm{ml})$ was drawn from the right ventricle of rabbits immediatcly after killing and bacteria were quantitatively cultured using pour plates, as described [5].

Statistics: The Wilcoxon two-sample rank sum test was used to calculate the significance of differences between the numbers of CFU recovered from VGs of rabbits with cathetcrs present or removed.

\section{Results}

Influence of catheter removal on development of viridans streptococcal IE: In the generally applied model of infective endocarditis catheters are inserted into the hearts of test animals 24 or $48 \mathrm{~h}$ before bacterial challenge, in order to establish a VG which can readily be colonized by bacteria $[4,6]$. We tested whether the continuous presence of the catheter was required for the development of IE. Indeed, in rabbits with catheters removed $24 \mathrm{~h}$ before bacterial challenge, the incidence of $\mathrm{IE}$ was strongly reduced for $S$. sanguis strains 1 and 2 (Table I). A preformed VG as such, without a catheter present apparently is not sufficient for development of streptococcal IE.

Population dynamics of $S$. sanguis on VGs in presence or absence of the catheter: To investigate the mechanism of the infection-potentiating effect of the catheter, we investigated colonization of the VGs by $S$. sanguis strains 1 and 2 as a function of time. The numbers of CFU 5 min after inoculation show that the initial colonization of VGs by both strains was not influenced by removal of the catheter prior to injection of bacteria (Fig. 1). In the presence of the catheter numbers of $S$. sanguis strain 1 (Fig. 1A) started to increase at $2 \mathrm{~h}$ after inoculation, resulting in rapid

TA B LE I Culture positive VGs 5 min and $48 \mathrm{~h}$ after inoculation of rabbits with $10^{5}$ Streptococcus sanguis or $10^{7}$ Staphylococcus epidermidis, in the $24 \mathrm{~h}$ model ${ }^{\mathrm{a}}$ of $\mathrm{IE}$.

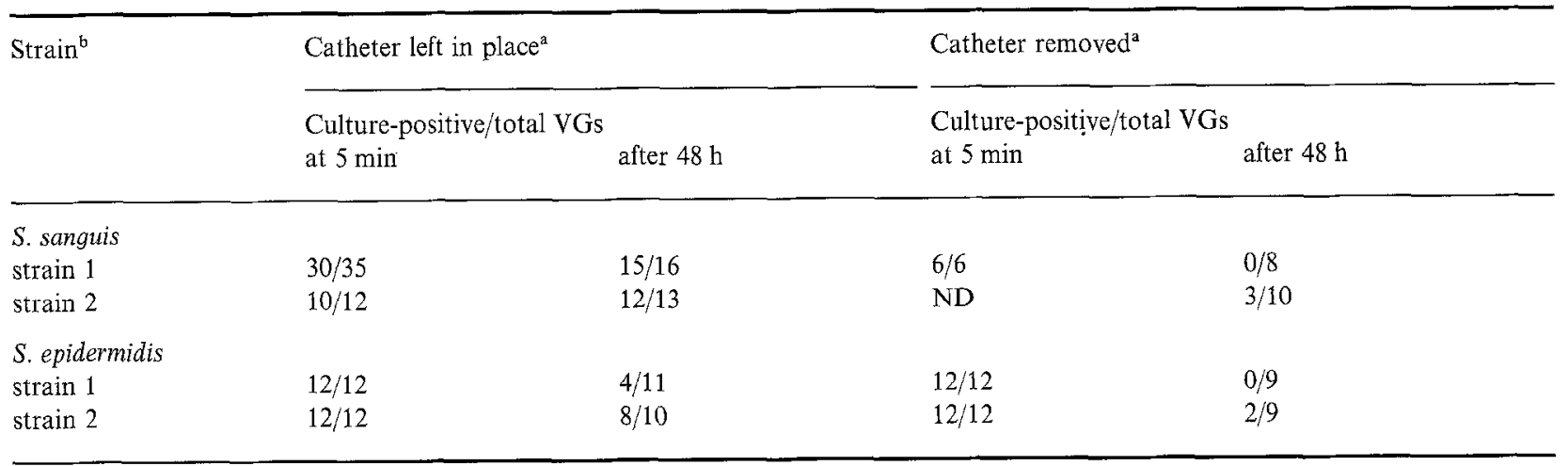

${ }^{a}$ In the experiments with $S$. sanguis, catheters were inserted into the left heart of rabbits, and were either left in place or removed after 24 h. After an additional $24 \mathrm{~h}$ bacteria were injected. In the experiments with $S$. epidermidis catheters were inserted and after $24 \mathrm{~b}$ either left in place or removed prior to bacterial challenge.

${ }^{b}$ Inocula of $10^{5}$ or $10^{7} \mathrm{CFU}$ of streptococci and staphylococci, respectively, were injected into a marginal ear vein. ND: not done. 
S. sanguis strain 1

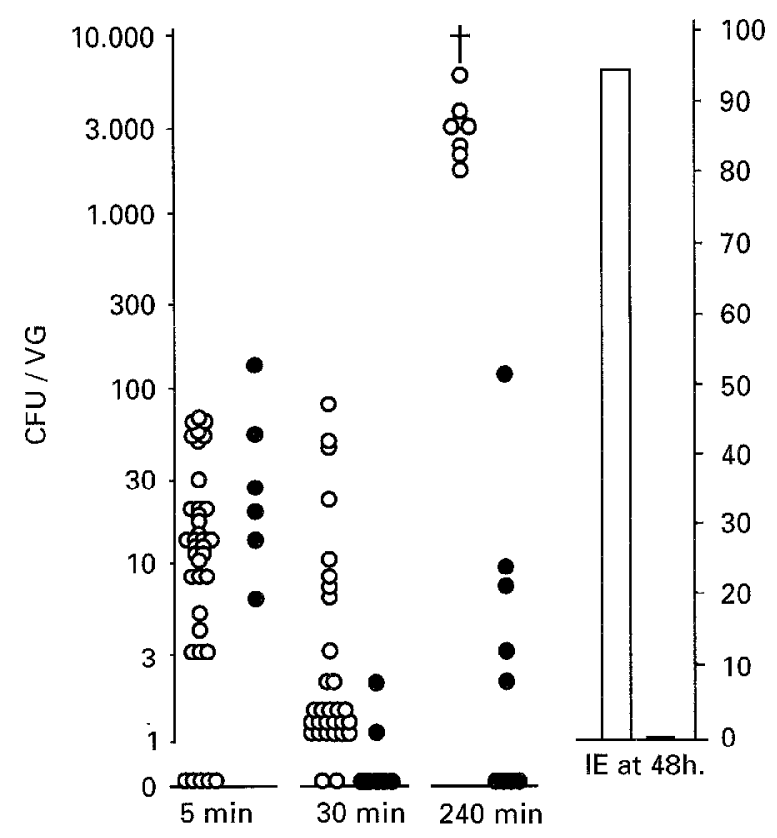

(a)
S. sanguis strain 2
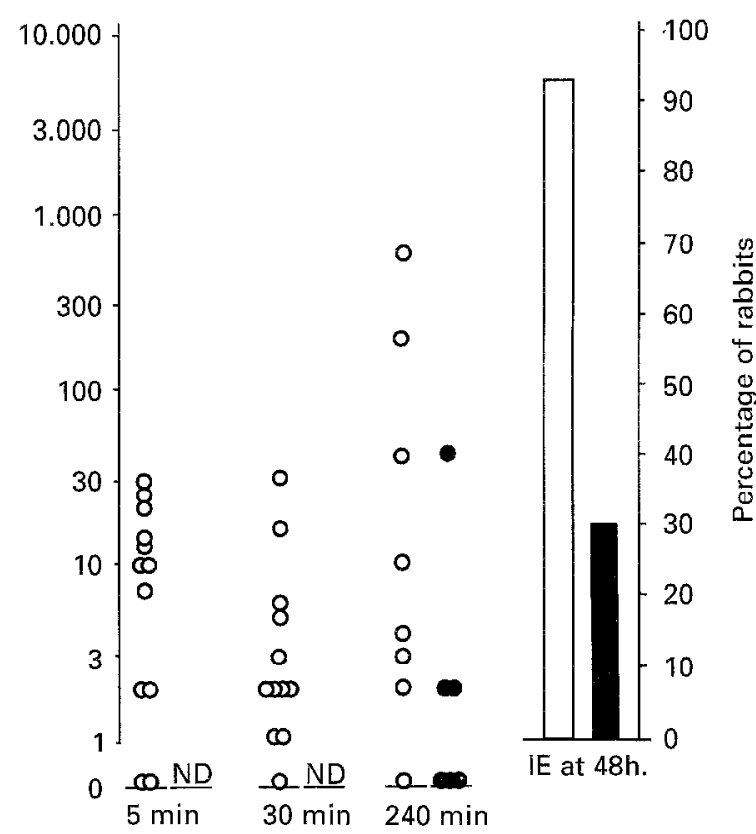

(b)

Figure I Numbers of CFU per VG and development of IE in rabbits with catheters present or removed before injection of $10^{5}$ streptococci. Catheters were inserted into the left heart of rabbits, and were either left in place (white circles) or removed after $24 \mathrm{~h}$ (black circles). After an additional $24 \mathrm{~h}$ bacteria were injected. A dagger indicates $p<0.01$ versus the values obtained at the corresponding time point in rabbits from which catheters were removed. ND means not done.

expansion of the population at $4 \mathrm{~h}$. When the catheter was removed, no such increase was observed with time, and bacteria disappeared from the VGs. $S$. sanguis strain 2 showed similar dynamics (Fig. 1B), but expansion of the population in the presence of the catheter was slower than for $S$. sanguis strain 1 .

Influence of catheter removal on development of IE due to S. epidermidis in the $24 \mathrm{~h}$ PVE model: Catheters inserted into the hearts of rabbits were either left in place or removed after $24 \mathrm{~h}$, prior to challenge with $S$. epidermidis strains 1 or 2 . Initial colonization of VGs was not influenced by removal of catheters, as all VGs were culture positive at $5 \mathrm{~min}$ after challenge. Final development of IE after $48 \mathrm{~h}$ was reduced in rabbits from which catheters had been removed (Table I).

Population dynamics of $S$. epidermidis in the presence or absence of a catheter in the $24 \mathrm{~h}$ PVE model: Although development of IE after $48 \mathrm{~h}$ due to S. epidermidis strains 1 and 2 was clearly enhanced by prolonged catheter presence, expansion of the populations on the VGs as observed with $S$. sanguis strain 1 had not yet started at $4 \mathrm{~h}$ after challenge (Table I, Fig. 2).

Role of catheter-colonization in catheter-enhanced bacterial population increase on VGs: Catheter colonization was studied in the $24 \mathrm{~h}$ model with $S$. sanguis strains 1 and 2, and S. epidermidis strains 1 and 2. $S$. sanguis strain 1 , which showed rapid population increase at $4 \mathrm{~h}$ (Fig. 1A), did not show a high initial colonization of the catheter $5 \mathrm{~min}$ after injection. Four hours after inoculation catheters were sterile (Fig. 3). The data for $S$. sanguis strain 2 were similar, although at $4 \mathrm{~h} 12 \%$ of the catheters still contained a low number of bacteria. The two S. epidermidis strains adhered to catheters more avidly at 5 min after inoculation, but were removed from most of the catheters at $4 \mathrm{~h}$. Apparently the catheters did not function as a reservoir of bacteria. This is in accordance with the fact that blood cultures always were negative at $4 \mathrm{~h}$.

Frequencies of IE due to staphylococci in the $24 \mathrm{~h}$ PVE model and the 30 min PVE model: Frequencies of IE due to S. epidermidis strains 1 and 2 in the $30 \mathrm{~min}$ model with catheters left in place were similar to the frequencies in the $24 \mathrm{~h}$ model with catheters left in place (strain 1: 9/23 (30 min model) and 4/11 (24 h model); strain 2: 21/25 (30 min model) and $8 / 10(24 \mathrm{~h}$ model), (Tables I and II). In the presence of a catheter, a preformed VG apparently is not a prerequisite for development of IE.

The frequencies of IE after $48 \mathrm{~h}$ in the presence of the catheter due to the 5 staphylococcal test strains in the 30 min PVE model showed considerable variation. S. saprophyticus SAP1 did not cause IE, and S. epidermidis strains 2 and 3 were more virulent than strains 1 and 4. Remarkably, 5 min after injection almost all AVs were culture positive for all strains (Table II). The strains thus have different abilities to persist in the presence of the catheter.

Influence of catheter removal on bacterial colonization of VGs in the 30 min PVE model: We tested whether prolonged presence of the catheter was required for development of IE in the $30 \mathrm{~min}$ PVE model. As in the $24 \mathrm{~h}$ PVE model, the frequencies of IE after $48 \mathrm{~h}$ in the 30 min PVE model were dramatically reduced when catheters were removed prior to inoculation (Table II). Strains 2 and 3, which caused the highest frequencies of IE when catheters were left in place, caused IE in $40 \%$ and $20 \%$ of rabbits from which catheters had been removed. 


\section{S. epidermidis strain 2}

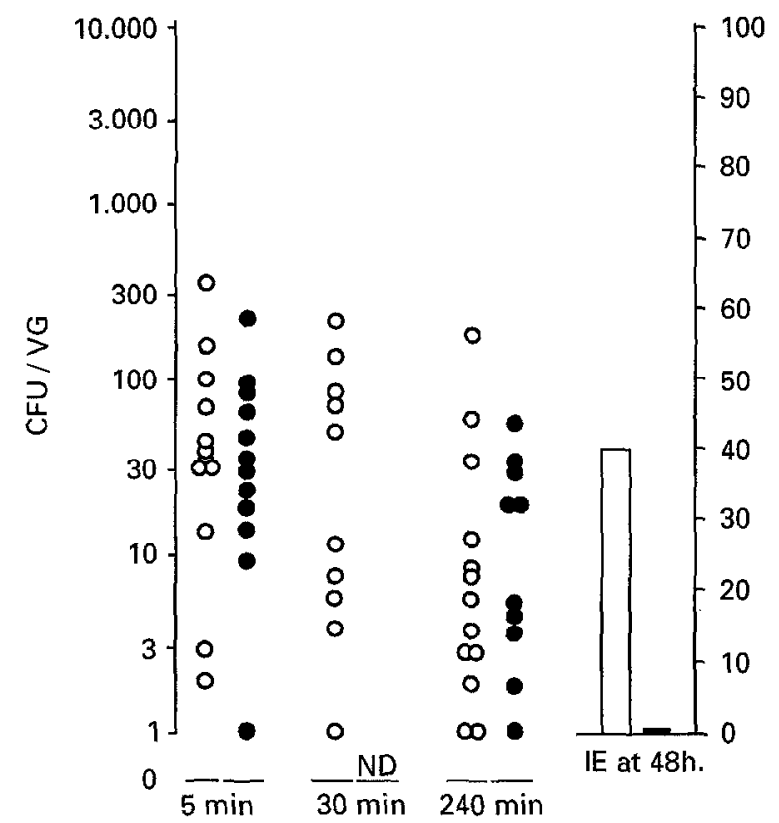

(a)

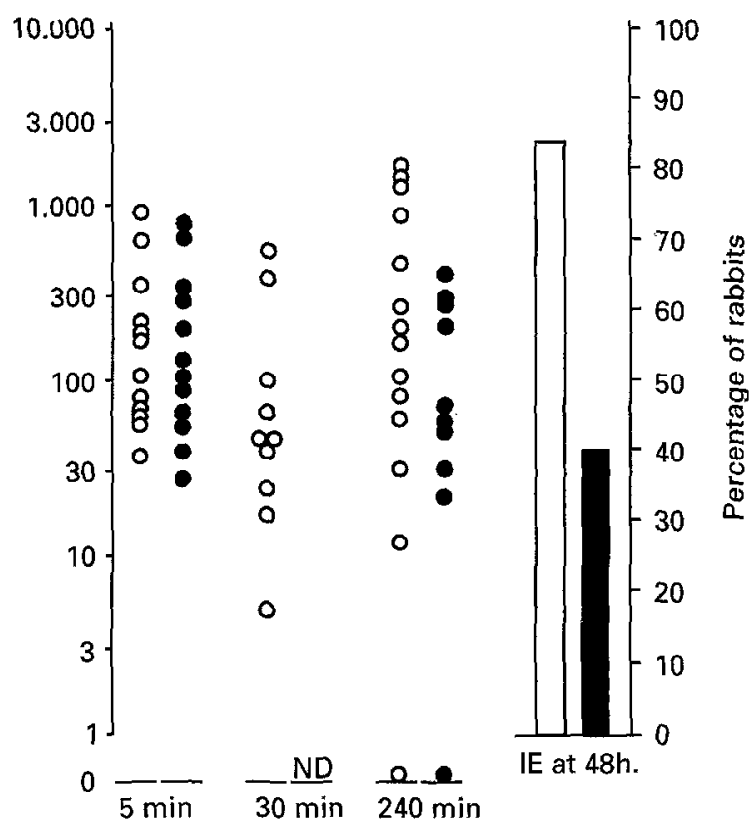

(b)

Figure 2 Numbers of CFU per VG and development of IE in rabbits with catheters present or removed before injection of $10^{7}$ staphylococci. Ca.theters were inserted and after $24 \mathrm{~h}$ either left in place (white circles) or removed (black circles) prior to bacterial challenge. ND means not done.

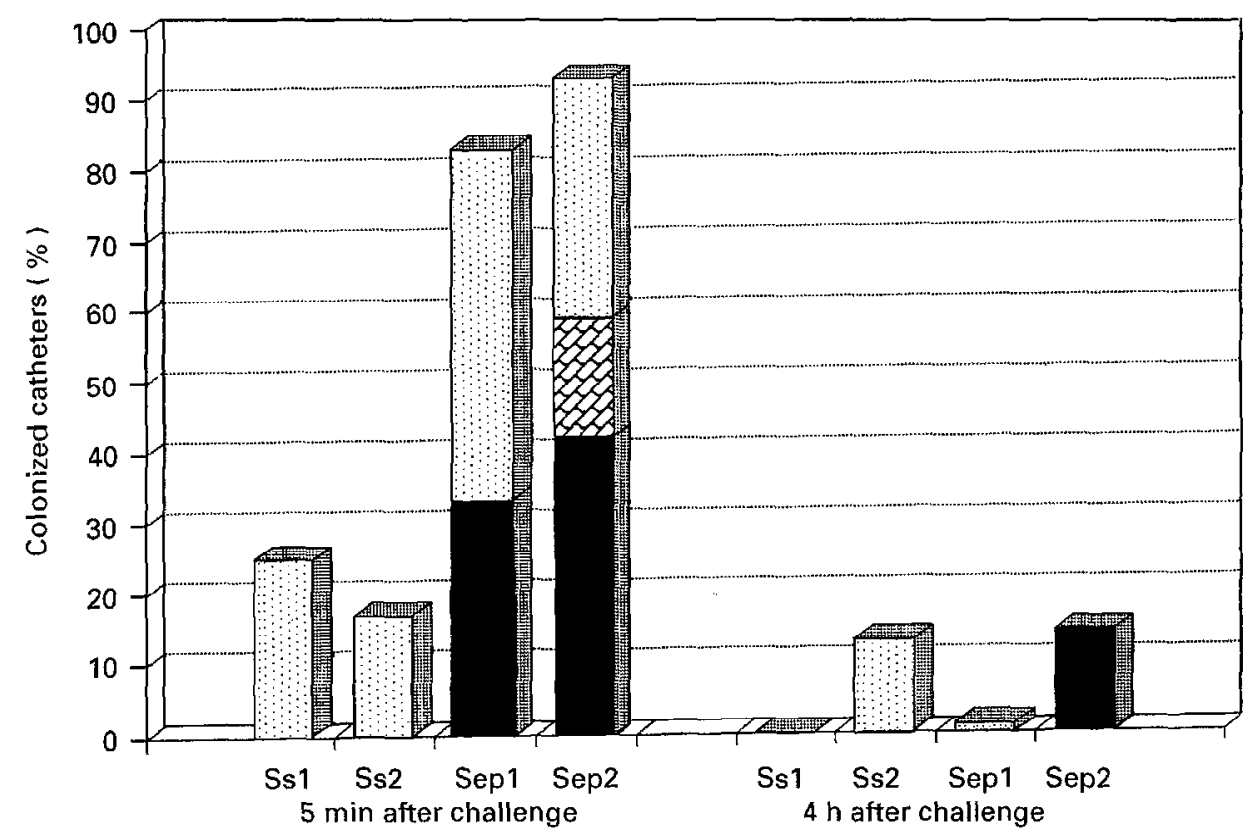

Figure 3 Percentage of culture-positive cathcters at $5 \mathrm{~min}$ and $4 \mathrm{~h}$ aftcr challenge of rabbits with $10^{5} \mathrm{~S}$. sanguis strain 1 (Ss1) or strain 2 (Ss2), or $10^{7}$ S. epidermidis strain 1 (Sep1) or strain 2 (Sep2). Catheters were inserted into the left heart of rabbits 48 or $24 \mathrm{~h}$ before challenge with

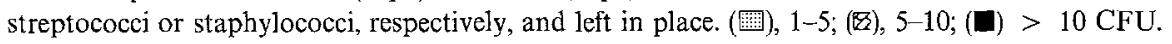

\section{Discussion}

Infective endocarditis generally is studied using animal models with catheters inserted into the heart. Insertion of the catheter is performed $24-72 \mathrm{~h}$ before injection of the bacteria. This causes formation of a sterile thrombotic VG, which is considered to be necessary for development of IE. This type of model mimics the situation of the natural valve endocarditis or late PVE. The trauma caused by the catheter can be considered to reffect the local traumata on valves and endocardium as caused by abberant blood flow due to congenital or acquired defects in the heart. However, in addition to the VG, the catheter itself may contribute to the development of $\mathrm{IE}$.

If the VG as such would be sufficient for development of IE, removal of the catheter $24 \mathrm{~h}$ after insertion, but before injection of bacteria, would not have any effect on the development of IE. However, removal of the catheter before bacterial challenge dramatically reduced the development of IE due to two $S$. sanguis strains and two $S$. epidermidis strains (Table I). This difference is not caused by differences 
TAB LE II Culture positive AVs at 5 min and VGs al 48 h after inoculation of rabbits with CN staphylococci in the 30 min PVE modcl ${ }^{\mathrm{a}}$ of IE

\begin{tabular}{|c|c|c|c|}
\hline \multirow[t]{2}{*}{ Strain ${ }^{h}$} & \multicolumn{2}{|c|}{ Catheter left in place ${ }^{a}$} & Catheter removed ${ }^{\mathrm{a}}$ \\
\hline & $\begin{array}{l}\text { Culture-p } \\
\text { at } 5 \text { min }\end{array}$ & $\begin{array}{l}\text { VVs or VGs } \\
\text { after } 48 \mathrm{~h}\end{array}$ & $\begin{array}{l}\text { Culture-positive/total VGs } \\
\text { after } 48 \mathrm{~h}\end{array}$ \\
\hline \multicolumn{4}{|l|}{ S. epidermidis } \\
\hline strain $1(100835)$ & $19 / 19$ & $9 / 23$ & $0 / 8$ \\
\hline strain 2 (100894) & $19 / 19$ & $21 / 25$ & $4 / 10$ \\
\hline strain $3(100892)$ & $13 / 15$ & $7 / 10$ & $2 / 10$ \\
\hline strain 4 (SL58) & $12 / 12$ & $3 / 10$ & $0 / 10$ \\
\hline \multicolumn{4}{|l|}{ S. saprophyticus } \\
\hline SAP1 & $9 / 9$ & $0 / 11$ & $0 / 8$ \\
\hline
\end{tabular}

${ }^{a}$ Catheters were inserted into the left heart of rabbits $30 \mathrm{~min}$ before bacterial challenge, and were either left in place or removed directly prior to bacterial challenge.

${ }^{b}$ Inocula of $10^{7} \mathrm{CFU}$ of staphylococci were injected into a marginal ear vein.

in initial colonization in the presence or absence of catheters (Fig. 1), but is related to the fact that only in the presence of the catheter bacterial populations increase with time (Figs 1 and 2). The presence of the VG as such thus is not sufficient for development of IE.

In most cases of early prosthetic valve endocarditis infections are due to contamination with bacteria, commonly $\mathrm{CN}$ staphylococci, which occurs during implantation $[9,10]$ or very shortly thereafter $[11]$. In order to simulate this situation, we designed a new model to study experimental early prosthetic valve endocarditis. In this model the catheter is inserted into the heart of rabbits only $30 \mathrm{~min}$ before injection of bacteria. At the time of inoculation a VG has not yet formed. When the catheters remained in place after bacterial challenge, the frequencies of IE due to 2 S. epidermidis strains in this 30 min PVE model were similar to those observed in the $24 \mathrm{~h}$ model (Tables I and II). Apparently, the presence of a preformed, macroscopic VG is not required for development of IE. Like in the $24 \mathrm{~h}$ PVE model, in the $30 \mathrm{~min}$ PVE model the presence of the catheter strongly enhanced development/onset of IE. Despite the absence of a preformed VG bacteria in the circulation may adhere to the freshly traumatized tissue where microthrombi are forming. They will then be embedded in the depositing platelets and fibrin of the growing VG, and will be protected from phagocytes. Since the 30 min model more realistically mimics the situation of early PVE than existing models of IE, this model can contribute to more accurate studies on the pathogenic mechanisms underlying early PVE due to $\mathrm{CN}$ staphylococci.

Our data seem to contradict those obtained in a rat model of endocarditis, in which catheters were inserted three days before bacterial challenge, and were either left in place or removed $30 \mathrm{~min}$ before injection of bacteria [12]. All animals challenged with $10^{7}$ Staphylococcus aureus or Streptococcus intermedius developed IE, regardless of the presence of the catheter. In the presence of the catheter however, higher population densities were found. The discrepancy between these observations and our finding that the catheter enhances infection due to $S$. sanguis and
S. epidermidis may be due to the fact that in rats the inoculum size of $10^{7}$ staphylococci or streptococci was too large to detect the infection-potentiating effect of the catheter [12]. As in our studies, an infection-potentiating effect of the catheter was noted when a serum-resistant Escherichia coli strain was used in rats $[12,13]$. The moment of catheter removal relative to the moment of injection of bacteria was shown to be of crucial importance for the development of IE due to E. coli. The frequency of IE ranged from 33\% when the catheter was removed $1 \mathrm{~h}$ before challenge, to $91 \%$ when removal took place $6 \mathrm{~h}$ after bacterial challenge [13]. Apparently the first hours after injection of bacteria are decisive for development of IE, which is strongly enhanced by the presence of a catheter.

The infection-potentiating effect of the catheters can be compared to other situations in which implanted biomaterials have been, shown to enhance infections [14-16]. We have shown that the catheter does not function as a reservoir of bacteria (Fig. 3). In the presence of the catheter however, bacterial populations start to increase $4 \mathrm{~h}$ after injection or shortly thereafter (Figs 1 and 2). This might be explained by either (i) reduced effectivity of local host defences, or (ii) enhanced growth of the bacteria, or a combination of both factors.

The most obvious element involved in rapid local host defence is phagocytosis by polymorphonuclear phagocytes (PMNs). Indeed PMNs isolated from tissue cages have been shown to be impaired in their phagocytic and bactericidal properties $[17,187$. However, these PMNs were isolated from the tissue cages 14 days after implantation, when the foreign body inflammatory response had been stabilized. Injection of Staphylococcus aureus bacteria into such tissue cages caused recruitment of fresh PMNs with full phagocytic/bactericidal capacity [17]. Furthermore, the role of PMNs in IE is considered to be limited by the fact that bacteria are shielded from the phagocytes by the fine fibrin/platelet meshwork of the VG.

A second explanation for the infection-potentiating effect of biomaterials could be the enhancement of growth of the bacteria. In the case of experimental IE the catheter causes continuous (sub)endothelial damage, which induces an inflammatory response. Due to 
the direct cell damage as well as the activation of inflammatory cells and endothelium, numerous potentially nutritious compounds will continuously be exuded in the vicinity of the catheter. As the wound environment [16] as well as several specific inflammatory mediators [19-21] have been shown to enhance bacterial growth, the inflammatory environment may be beneficial for bacterial population expansion. Thus, the presence of the biomaterial may shift the balance of bacterial population decrease by the host defence versus population increase by enhanced growth to the benefit of the bacteria, thereby potentialing for infection.

\section{References}

1. A. W. KARCHMER and A. L. BISNO in Infections associated with indwelling medical devices, edited by A. L. BISNO and F. A. WALDVOGEL, (A.S.M., Washington, 1989), p. 129.

2. K. H. MAYER and C. S. SCHOENBAUM, Prog. Cardiovasc. Dis. 25 (1982) 43.

3. J. DANKERT, A. H. HOGT and J. FEIJEN, CRC Crit. Rev. Biocomp. 2 (1986) 219

4. D. T. DURACK and P. B. BEESON, Br. J. Exp. Pathol. 53 (1972) 44.

5. J. DANKERT, J. VAN DER WERFF, S. A. J. ZAAT, W. JOLDER SMA. D. KLEIN and J. HESS, Infect. Immun. 63 (1995) 663.

6. J, HESS, J. DANKERT and D. DURACK, J. Antimicrob. Chemother. 11 (1983) 555.

7. A. H. HOGT, J. DANKERT and J. FEIJEN, FEMS Microbiol. Lett. 18 (1983) 211.
8. P. BROKKE, J. FEIJEN and J. DANKERT in Pathogemesis of wound- and biomaterial-associated infections, edited by T. WADSTRÖM, I. ELIASSON, I. HOLDER and A. LJUNGH (Springer Verlag, London, 1990) p. 419.

9. P. J. VAN DEN BROEK, A. S. LAMPE, G. A. M. BERBÉE, J. THOMPSON and R. P. MOUUTON, Br. Med. J. 291 (1985) 949.

10. B. M. BOYCE, G. POTTER-BYNOE, S. M. OPAL, L. DZIOBEK and A. A, MEDEIR OS, J. Infect. Dis. 161 (1990) 493.

11. R. M. KLUGE, F. M. CALIA, J. S. MCLAUGHLIN and R. B. HORNICK, J. Am. Med. Assoc. 230 (1974) 1415.

12. E. HÉRAIEF, M. P. GLAUSER and L. R. FREEDMAN, Infect. Immun. 37 (1982) 127.

13. B. YERSIN, M. GLAUSER. P. A. GUZE, L. B. GUZE and L. R. FREEDMAN, Infect. Immun. 56 (1988) 1273.

14. S. D. ELEK and P. E. CONEN, Br. J. Exp. Pathol. 38 (1957) 573.

15. R. C. JAMES and C. M. MACLEOD, ibid., 42 (1961) 266.

16. W. C. NOBLE, Br. J. Exp. Pathol. 46 (1965) 254.

17. W. ZIMMERLI, F, A. WALDVOGEL, P. VAUDAUX and H. E. NYDEGGER. J. Infect. Dis. 146 (1982) 487.

18. W. ZIMMERLI, P. D. LEW and F. A. WALDVOGEL, J. Clin. Invest. 73 (1984) 1191

19. R. PORAT, D. B. CLARK, S. M. WOLFF and C. A. DINARELLO, Science 254 (1991) 430.

20. M. DENIS, Cell. Immunol. 141 (1992) 182.

21. M. DENIS, D. CAMPBELL and E. O. GREGG, Infect. Immun. 59 (1991) 1853.

Received 29.June

and accepted 4 July 1995 